\title{
Cell proliferation activity and prognostic index in squamous cell lung carcinoma
}

\author{
José Antonio Alvarez-Riesgo a , Andrés Sampedro ${ }^{\mathrm{b}, *}$, Radhamés Hernández ${ }^{\mathrm{a}}$, \\ María Victoria Folgueras ${ }^{\mathrm{c}}$, Ana Salas-Bustamante ${ }^{\mathrm{b}}$ and Antonio Cueto ${ }^{\mathrm{a}}$ \\ ${ }^{a}$ Departamento de Medicina, Universidad de Oviedo, Facultad de Medicina, C/ Julián Clavería s/n, \\ 33006 Oviedo, Spain \\ ${ }^{\mathrm{b}}$ Servicio de Citometría, Hospital Central de Asturias, Bloque Polivante A, la Planta, C/ Celestino \\ Villamil s/n, 33006 Oviedo, Spain \\ ${ }^{\mathrm{c}}$ Servicio de Anatomía Patolögica II, Hospital Central de Asturias, C/ Celestino Villamil s/n, \\ 33006 Oviedo, Spain
}

Received 16 December 1997

Revised 14 April 1998

Accepted 5 June 1998

\begin{abstract}
Flow Cytometry (FC) has been incorporated into cancer research in relation to its prognostic value together with histological parameters and TNM stages. We have studied by means of FC the cell cycle of 132 samples from male patients with Squamous Cell Lung Carcinoma (SQCLC). All of the patients received curative surgery and the clinical follow-up was 60 months. The clinical and cytometric parameters were evaluated in order to predict the patients' outcome. The presence of tumoural recurrence and the tumoural stage showed statistical significance associated with survival. The multivariant analysis reveals radiotherapy $(p=0.004)$ as protective variable and the high S-phase fraction (SPF) $(p=0.001)$ and stage IIIA $(p=0.012)$ as risk factors. The SPF appears as an independent prognostic factor for overall survival time. We can build a prognostic index representative of different prognostic groups, which allows us to improve the individual monitoring of these patients.
\end{abstract}

Keywords: Squamous cell lung carcinoma, flow cytometry, cell proliferation, DNA ploidy, prognosis

\section{Introduction}

Lung cancer is an important public health problem in our region, with an incidence rate in males of 112.40 per 100,000 and a male/female occurrence ratio of 10/1 [10]. From the histological point of view, $45 \%$ of the non-small cell lung carcinomas (NSCLC) are squamous carcinomas. At present, the anatomic description of dissemination and tumoural aggressiveness precision are the two main sets of factors which allow us to estimate the prognosis of the patients [12]. However, the variability in the survival rate within the same stages, proves that we still need to find other prognostic factors which can determine which patients are most at risk to suffer a recurrence of the disease [5,23].

Technological development has had a great impact on the precision of tumoural stage and on the overall survival rate of patients [11,31]. The use increasingly sensitive image analysis methods has facilitated the

\footnotetext{
${ }^{*}$ Address for correspondence: Dr. A. Sampedro, Servicio de Citometría, Hospital Central de Asturias, Bloque Polivante A, 1a Planta, C/ Celestino Villamil s/n, 33006 Oviedo, Spain. Tel.: +34 851036 60; Fax: +34 851036 58; E-mail: citometria@lupo.quimica.uniovi.es.
} 
improvement of the survival rate in SQCLC due to a more precise identification of the subsidiary surgical treatment of these patients [22]. As the long-term intervention results and treatment responses are based on inherent biological factors within the tumoural cells, it is becoming more and more important for us to concentrate our research efforts on the tumoural biology of lung cancer [6].

DNA ploidy and tumour cell proliferation activity estimated by FC have been considered potential indicators of survival and treatment response in SQCLC [1,32,36,39]. In some of the SQCLC series, overall survival varies depending on the ploidy, regardless of the stage $[16,26,35]$. Tumoural recurrence in SCQLC has been reported 50\% lower than in other NSCLC [33].

The reported variability of the prevalence and prognostic significance of DNA aneuploidy could be related to the number of samples analysed, the methodological differences and the histological types $[8$, $16,17,32]$.

The prognostic value of the DNA aneuploidy can be completed with the analysis of the cell proliferation activity estimated using FC according to the percentage of cells in S-phase. The increasing proliferation activity has a negative effect on the survival rate [35]. In this way, the neoplasias with a high rate of cells in S-phase are more likely to develop metastasis, regardless of the histological differentiation, stage of the disease, or the type of treatment [37]. The cytometric information obtained from the cell cycle analysis can be combined with the information provided by the tumoural extension and other variables so as to build up a Prognostic Index (PI) [14].

Because of the male/female incidence and the histologic frequency, we carried out a retrospective study on 132 male patients with SQCLC who have received curative surgery to establish the prognostic significance of these cytometric variables. The final aim of our study was to establish objective and reproducible follow-up parameters, complementary to the clinicopathological ones which allow us to assess, in each case, the potential aggressiveness of the neoplasia and the corresponding therapeutic monitoring.

\section{Materials and methods}

\subsection{Patients}

One hundred and thirty-two males with SQCLC treated by curative surgery, were studied and included in the tumour archives at the Hospital General de Asturias (HGA) from January 1, 1985 to December 31, 1989. The surgery was planned as curative in patients in stages I, II and IIIA, according to the TNM classification of the Fourth World Wide Lung Cancer Conference [19]. A further reclassification was carried out after pathological study. The original diagnosis was established by radiography, cytology of sputum and/or bronchoscopy. The information was completed with preoperative and postoperative pathological examinations.

Regarding the complementary treatment, radiotherapy decision was taken according to the pathologic study, incorporating the clinical staging parameters such as tumour size, grading of differentiation, vascular and pleural invasion and tumour necrosis. Chemotherapy was not given to the patients.

The follow-up of the patients continued for 60 months after the date of surgery. A complementary procedure was established for those patients for whom we had no information during the follow-up period. At first, they were investigated by means of the program of oncological patients treated with opiate derivatives, whose mandatory register is kept by the regional medical authorities. Finally, the Regional Statistical Decease Bulletins (RSDB) were assessed during a 5 year period after surgery, recording the 
cause of death in order to complete the follow-up. The patients lost in our study were 9/132 (6.8\%) distributed in a uniform way during the periods, 3 (1985), 2 (1986), 2 (1987), 2 (1989), and the cause is the loss of clinical history information.

The tumoural recurrence was confirmed by biopsy, cytology or fine needle aspiration. The relapse free time was obtained by subtracting the surgical resection date from the recurrence date.

\subsection{Flow cytometry}

The flow cytometric analysis was carried out by the Cytometry Service of the University of Oviedo from the material embedded in paraffin and archived in the Pathology Service of the HGA. A detailed description of the technique used has been published [27]. To select the blocks we revised for each patient all the slides available stained with hematoxylin-eosin, selecting those with a greater proportion of tumour and a lower rate of inflammatory component. When possible, sections from two or more blocks were taken. Three $50 \mu \mathrm{m}$ thick sections were obtained from each block of tissue. The deparaffination was carried out with xylene for $35-40 \mathrm{~min}$ at $70^{\circ} \mathrm{C}$, and left at room temperature for $10 \mathrm{~min}$. Ethanol was used in decreasing concentration $(100,96,70 \%)$ for $10 \mathrm{~min}$ in each step, later washing the sample with a PBS buffer and centrifuging it at $300 \times \mathrm{g}$ for $10 \mathrm{~min}$. After centrifugation, enzymatic disaggregation was performed in pepsin solution (Pepsin A, EC 3.4.23.1, Sigma, St. Louis, MO, USA) for $30 \mathrm{~min}$ in a shaking water bath at $37^{\circ} \mathrm{C}$. In addition, the samples were mechanically dissociated using a $5 \mathrm{ml}$ syringe and with a 20 gauge needle, drawn in and out of the tube several times. The single cells and nuclei obtained were then filtered through a nylon mesh $(70 \mu \mathrm{m})$ and stained with propidium iodide according to the Vindelöv technique [34].

A FacScan cellular analyser from Becton Dickinson was used which was equipped with an argon-ion laser light source, with excitation at a wave length of $488 \mathrm{~nm}$, and three fluorescence detectors, selecting the FL2 with a fluorescent emission band of about $585 \mathrm{~nm}$. To obtain and analyze the data we used the Cellfit software 2.0.2 from Becton Dickinson. Tumour sample acquisition was carried out together with a DNA diploid control, using lymphocytes from tonsil embedded in paraffin and processed at the same time as the tumoural suspensions. Should the presence of aneuploid tumours be questioned with more than one population, a mixed sample of tumour and control was prepared. From each sample, 10,000 15,000 cells were analysed [4] and the CV was always found to be lower than $6 \%$. The number of events were those obtained after the exclusion of debris and aggregates. The histograms obtained were then interpreted by an analyst with no prior knowledge of the clinical characteristics of the neoplasia. The following were taken as cytometric variables: DNA ploidy, DNA Index (DI) and SPF. The adjustment of debris and aggregates were established by an electronic gate. In all the DNA diploid cases RFIT model was used in the assessment of S-phase, and POLY model in the DNA aneuploid ones. The cases with DI between 0.9 and 1.1 were considered as DNA diploids, less than 0.9 or greater than 1.10 as DNA aneuploids, and between 1.9 and 2.1 as DNA tetraploids.

\subsection{Statistical analysis}

The data was analysed using the SPSS/PC ${ }^{+}$version 4.01 and Egret version 0.26.6 Pecan. The qualitative variable analysis was carried out using the chi square test. The Cox model [7] was used for regression analysis. The formula applied was $h\left(t, x_{i}\right)=h_{0}(t) \mathrm{e}^{\beta x}$, where $h\left(t, x_{i}\right)$ represents the hazard function or hazard rate, with values in the explicative variables $(x)$ in the time $(t), h_{0}(t)$ is the function of the reference hazard rate ("baseline" or "underlying hazard function") and $\mathrm{e}^{\beta x}$ represents an exponential function 
whose exponent represents the linear combination of the explicative variables $\left(x_{i}\right)$. The $p$ value to enter was established at 0.05 , and $p$ value to remove at 0.15 . The prognostic index was built from the multivariant model. The results of this analysis have been used to define a PI, expressed by the formula: $\mathrm{PI}=\sum_{i} \beta_{i} X_{i}$. The PI expressed as a continuous quantitative variable, changes into a negative scale, and was thus converted into a positive scale in order to aid understanding. To represent the survival according to the PI, the results were categorized by quartiles (Q), and the differences were analysed with the log-rank technique. From the variables examined in the Cox regression models, the relapse free time, measured in months, and the rate of cells in S-phase were considered as continuous quantitative variables. The tumoural recurrence and the application of radiotherapy were expressed as dichotomic variables, and the tumoural stage as an ordinal variable.

\section{Results}

The patients in our study were homogeneously distributed throughout our 5 year investigation, with the 55-64 year olds being the most important age group, but numerically close to the 65-74 year olds (Table 1). Almost all of the patients (98.8\%) were smokers. Regarding the tumoural stage, $65.9 \%$ of the

Table 1

General description of the sample

\begin{tabular}{lrrr}
\hline Variable & $N=132$ & $\%$ & $p$ value \\
\hline Age (years) & & & $<0.001$ \\
$\quad<55$ & 16 & 12.1 & \\
$55-64$ & 55 & 41.7 & \\
$65-74$ & 51 & 38.6 & \\
$>74$ & 10 & 7.6 & \\
Smoking status & & & $<0.001$ \\
$\quad$ Non-smoker & 1 & 0.6 & \\
Smoker & 130 & 98.8 & \\
Ex-smoker & 1 & 0.6 & \\
Stage & & & $<0.001$ \\
$\quad$ Stage I & 87 & 65.9 & \\
$\quad$ Stage II & 11 & 8.3 & \\
Stage IIIA & 34 & 25.8 & \\
Cellular differentiation & & & $<0.001$ \\
$\quad$ Well & 11 & 8.3 & \\
$\quad$ Moderate & 82 & 62.1 & \\
Poor & 39 & 29.6 & \\
DNA ploidy & & & NS \\
Diploid & 69 & 52.2 & \\
Aneuploid & 63 & 47.8 & \\
Surgery & & & $<0.001$ \\
Lobectomy & 57 & 43.2 & \\
Pneumonectomy & 69 & 52.3 & \\
Others & 6 & 4.5 & \\
Status & & & $<0.001$ \\
$\quad$ Alive & 48 & 36.4 & \\
$\quad$ Dead & 84 & 63.6 & \\
\hline
\end{tabular}


Table 2

Univariant analysis of squamous cell lung carcinoma

\begin{tabular}{|c|c|c|c|}
\hline Variable & $\mathrm{RR}^{*}$ & CI (RR) & $p$ value \\
\hline $\begin{array}{l}\text { Tumour relapse } \\
\text { (no vs. yes) }\end{array}$ & 3.979 & $2.522-6.278$ & 0.001 \\
\hline $\begin{array}{l}\text { Stage } \\
\quad \text { I vs. II } \\
\text { I vs. IIIA }\end{array}$ & $\begin{array}{l}1.909 \\
2.472\end{array}$ & $\begin{array}{l}1.000-3.673 \\
1.578-3.871\end{array}$ & $\begin{array}{l}0.051 \\
0.001\end{array}$ \\
\hline $\begin{array}{l}\text { Relapse free time } \\
\quad \text { (months) }\end{array}$ & 0.940 & $0.928-0.953$ & 0.001 \\
\hline $\begin{array}{l}\text { Radiotherapy } \\
\text { (no vs. yes) }\end{array}$ & 1.581 & $0.998-2.503$ & 0.060 \\
\hline $\begin{array}{l}\text { DNA ploidy } \\
\quad \text { (diploid vs. aneuploid) }\end{array}$ & 1.230 & $0.799-1.893$ & 0.347 \\
\hline $\begin{array}{l}S P F \\
\quad \text { (percentage) }\end{array}$ & 1.011 & $0.997-1.024$ & 0.147 \\
\hline
\end{tabular}

Table 3

Multivariant analysis of squamous cell lung carcinoma

\begin{tabular}{lccc}
\hline Variable & $\mathrm{RR}^{*}$ & $\mathrm{CI}(\mathrm{RR})$ & $p$ value \\
\hline $\begin{array}{l}\text { Radiotherapy } \\
\quad \text { (no vs. yes) }\end{array}$ & 0.361 & $0.179-0.726$ & 0.004 \\
$\quad$ & & & \\
Stage & 1.160 & $0.456-2.892$ & 0.750 \\
$\quad$ I vs. II & 2.439 & $1.220-4.877$ & 0.012 \\
$\quad$ I vs. IIIA & & & \\
$\quad \begin{array}{l}\text { Relapse free time } \\
\quad \text { (months) }\end{array}$ & 0.927 & $0.910-0.944$ & 0.001 \\
$\quad$ & & & \\
$\begin{array}{l}\text { SPF } \\
\quad \text { (percentage) }\end{array}$ & 1.026 & $1.011-1.042$ & 0.001 \\
\hline${ }^{*}$ Cox's regression. RR: relative risk; CI: confidence interval.
\end{tabular}

patients were in stage I, $8.3 \%$ in stage II and $25.8 \%$ in stage IIIA. Only $8.3 \%$ of the cases were identified as well-differentiated with $62.1 \%$ moderately differentiated and $29.6 \%$ poorly differentiated.

From the total of 132 cases studied, 52.2\% were diploids (mean of S-phase fraction $14.154 \%$ and SD 10.294) and $47.8 \%$ aneuploids (mean of S-phase fraction $12.147 \%$ and SD 12.473). We found significant differences in the S-phase fraction from DNA diploid and aneuploid tumours $(p=0.0006)$. Regarding the type of surgery, pneumonectomy was the most frequently used at $52.3 \%$. This resulted in $36.4 \%$ of the patients still being alive after 5 years.

In the univariant analysis the clinical variables: presence of tumoural recurrence, tumoural stage and tumoural relapse free time, all showed statistical significance associated with the patients' survival (Table 2). In this table we can see the reduction of overall survival time with tumoural recurrence and stage IIIA. 


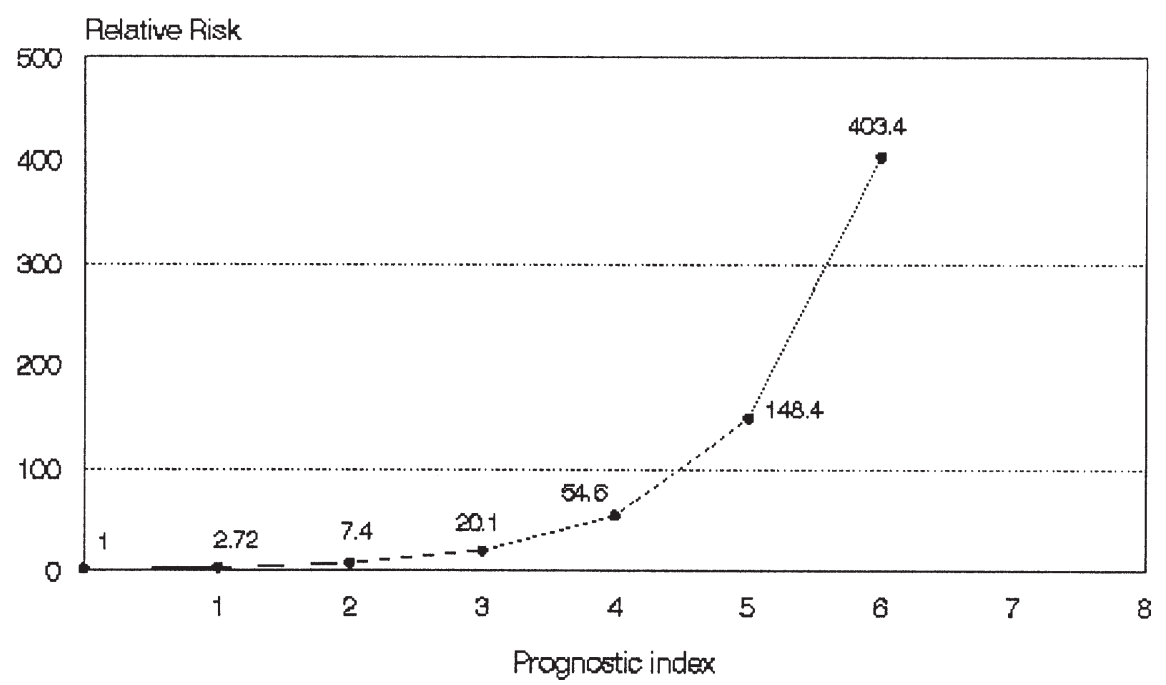

Fig. 1. Prognostic index and dead risk.

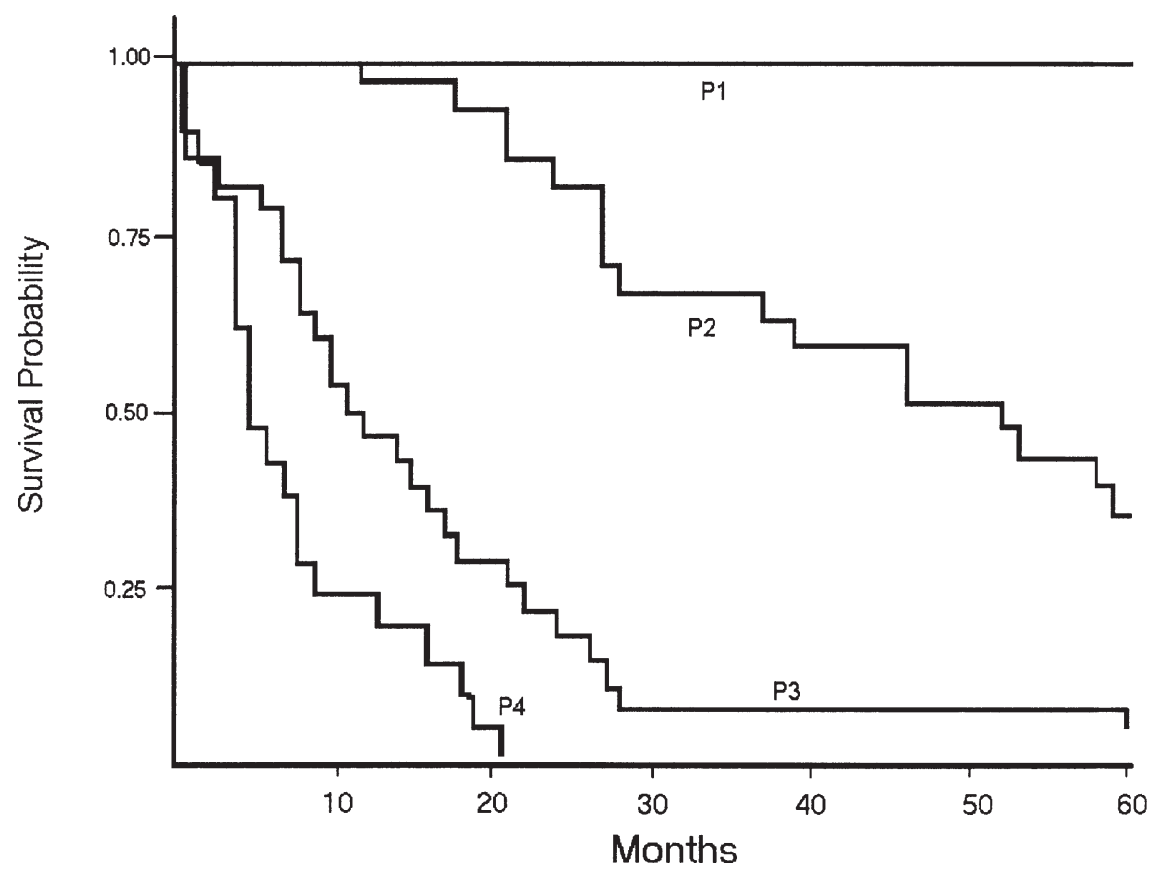

Fig. 2. Survival analysis for prognostic index quartil.

The multivariant analysis (Table 3) includes radiotherapy, tumoural stage and relapse free time as clinical variables and the SPF as the cytometrical one. Radiotherapy $(p=0.004)$ and the relapse free time ( $p=0.001)$ are clear protective variables, and the high SPF $(p=0.001)$ and stage IIIA $(p=0.012)$ are clearly risk factors.

The risk of dying as predicted by the PI (Fig. 1) show an exponential evolution. Categorizing the prognostic index by quartiles, the survival rate decreases with the change of quartile; this change is 


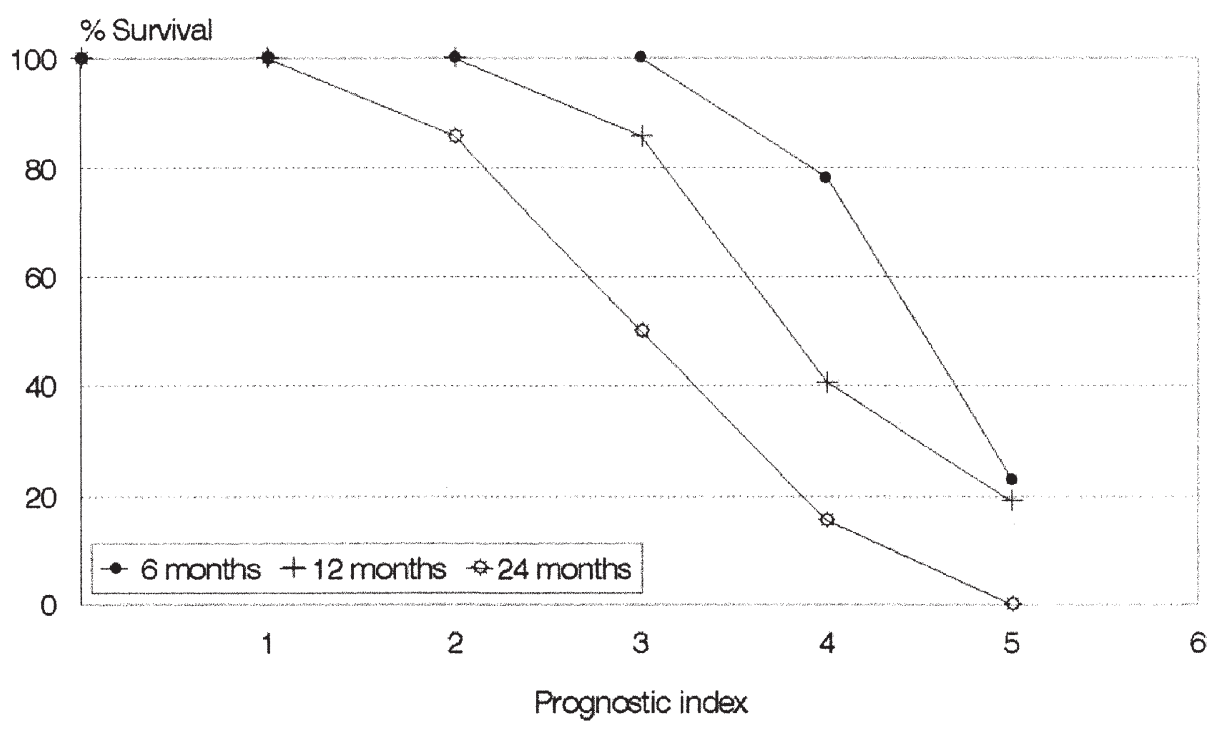

Fig. 3. Survival and prognostic index at 6,12 and 24 months.

statistically significant $(p<0.001)$ (Fig. 2). The results in the evaluation of survival probability at 6,12 and 24 months confirm the previous results (Fig. 3).

\section{Discussion}

Of the total number of patients, $98.8 \%$ were smokers, which represents a very similar proportion to the $95-98 \%$ obtained by other authors [20,21]. In the tracheobronchial area, $90 \%$ of the tumours are attributable to smoking, estimating the time of empirical induction to be between 20-40 years from the beginning of smoking to the maximum disease incidence $[3,24,30]$. Thus, our cases correspond to patients starting in their 50s and 60s, with an accumulated incidence of $53.8 \%$ of the patients at the age of 64.

In our series, $65.9 \%$ of the patients were in stage I of the disease. The definition of the degree of cellular differentiation is complex and a controversial subject among pathologists, with a tendency to establish a high rate of tumours as moderately differentiated. We found $62.1 \%$ of SQCLC to be moderately differentiated, similar to the results obtained by other authors [15], and only $8.3 \%$ to be well differentiated tumours.

At present, it is agreed that the main factors affecting the prognosis of patients with lung cancer is the TNM staging with complementary information on the differentiation degree, vascular and pleural invasion, and growth rate. In the univariant analysis (Table 2) only some clinical variables show statistical significance. Our multivariant model (Table 3) includes clinical variables and incorporates the SPF results obtained by FC. The TNM and the SPF become risk factors, increasing the risk of death in 1.026 per unit increase in SPF. This is only evident for the TNM in stage IIIA (2.439). The similarities between the rate of death in stages I and II of the TNM can be related to the problems of staging $[18,25]$. The tumoural stage has shown an independent prognostic significance in different investigations related to SQCLC [23] and the whole of NSCLC [9].

The multivariant analysis of prognostic factors contributes to the understanding of the interrelation between them, identifying subgroups of patients who can take advantage of the different therapeutic 
strategies [28,29]. In some cases, variables which are not significant in the univariant analysis are included in the multivariant analysis, due to the adjusting of the effect of other variables included in the model. This is also the case with the SPF, the inclusion of which improves the precision of the effect of variables included in the model (Table 3). The increasing relapse free time and the application of radiotherapy acted as protective variables in our patients. Although the benefit of radiotherapy application in lung cancer stages II and III is contradictory [38] in our cases, this proves to be a protective variable, reducing the risk of death by two thirds.

In the formulation of a model, spurious results can be obtained if we include a large number of variables, with the subsequent loss of accuracy and efficiency [13]. This risk is low if we consider as predictive variables $5-10 \%$ of the events. Our model considers 4 prognostic variables, representing $4.7 \%$ of deaths following the recommendations of different authors. Since none of the selected variables in the multivariate analysis contradict the clinical knowledge or the known biological principles on SQCLC, we accept that their inclusion in a prognostic model can be reasonable, because there is no random association with the survival of any variables of the model.

The prognostic factors observed in this study fulfil the main essential properties for their application [12]: they show a high correlation with the patient's prognosis and a good methodological reproducibility. Furthermore, these factors can be used to predict individual prognosis and formulate therapeutic strategies [13].

One of the final objectives of building regression models is the obtaining of a prognostic index which can summarize all the information and represent the survival probability, or any other result of interest by combining different prognostic factors. In this way, its use could be studied in the implementation of treatment plans, clinical trial, or the design of control strategies in the follow-up of the patients [2].

From the explanatory variables of our multivariate model we have built a PI which enables us to appreciate that an increase in its value is related to an increase in the relative risk of mortality of 2.72 for each prognostic unit (Fig. 1). Low values on the PI are due to a greater importance of protective variables: application of radiotherapy, relapse free time, the first stages of the TNM and the low rate of SPF.

By dividing the PI into quartiles (Fig. 2), significant statistical differences $(p<0.001)$ are marked in relation to survival. A clear decrease in the survival in higher quartiles can be seen.

In Fig. 3 we represent the survival probability at 6, 12 and 24 months, and so we could establish three prognostic groups with cut-off points at PI 2 and 3.5, and term them good, regular and bad prognosis. This possibility of building independent prognostic groups improves the efficiency of the patients' control, establishing different standards for the observation depending on the expected evolution of the disease.

\section{Acknowledgements}

This work was supported in part by a grant from the Vicerrectorado de Investigación, Universidad de Oviedo, Project DF/93/219/60. The oral presentation at the 5th ESACP Congress in Oslo, May 25-29, 1997, was partly based on the results of this paper.

\section{References}

[1] S. Abe, Y. Tsuneta, K. Makimura and Y. Kawakami, Nuclear DNA content as an indicator of chemosensitivity in small-cell carcinoma of the lung, Anal. Quant. Cytol. Histol. 9 (1987), 425-428.

[2] P.K. Andersen, Survival analysis 1982-1991: the second decade of the proportional hazards regression model, Stat. Med. 10 (1990), 1931-1941 
[3] C.E. Bartecchi, T.D. Mackenzie and R.W. Schrier, The human costs of tobacco use (first of two parts), New Engl. J. Med. 330 (1994), 907-912.

[4] E. Bergers, P.J. van Diest and J.P.A. Baak, Reliable DNA histogram interpretation. Number of nuclei requiring measurement with flow cytometry, Anal. Quant. Cytol. Histol. 19 (1997), 277-284.

[5] F.A. Carey, U.S. Prasard, W.S. Walkers, E.W.J. Cameron, D. Lamb and C.C. Nird, Prognostic significance of tumour deoxyribonucleic acid content in surgically resected small-cell carcinoma of lung, J. Thorac. Cardiovasc. Surg. 103 (1992), 1214-1217.

[6] D.N. Carney, The biology of lung cancer, Curr. Opin. Oncol. 4 (1992), 292-298.

[7] D.R. Cox, Regression models and life-tables (with discussion), J. Roy. Stat. Soc. Ser. B 34 (1972), 187-220.

[8] H. Dazzi, N. Thacher, P.S. Hasleton and R. Swindell, DNA analysis by flow cytometry in nonsmall cell lung cancer: relationship to epidermal growth factor receptor, histology, tumour stage and survival, Respir. Med. 84 (1990), $217-223$.

[9] J. Deslauriers et al., Carcinoma of the lung. Evaluation of satellite nodules as a factor influencing prognosis after resection, J. Thorac. Cardiovasc. Surg. 97 (1989), 504-512.

[10] M. Echeverria and R. Alonso de la Torre, Incidencia del cáncer en Asturias en 1988-1989, Consejería de Servicios Sociales, Principado de Asturias, 1994 (unpublished).

[11] A.R. Feinstein, D. Sonin and C.K. Wells, The Will Rogers phenomenon. Stage migration and the new diagnostic techniques as a source of misleading statistics for survival cancer, New Engl. J. Med. 312 (1985), 1604-1608.

[12] P. Fielding, C. Fenoglio-Preiser and L. Freedman, The future of prognostic factors in outcome prediction for patients with cancer, Cancer 70 (1992), 2367-2377.

[13] F. Harrel, K. Lee, D. Matchar and T. Reichert, Regression models for prognostic prediction: advantages, problems and suggested solutions, Cancer Treat. Rep. 69 (1985), 1071-1077.

[14] P. Hermaneck, R.V. Hutter and L.H. Sobin, Prognostic grouping: the next step in tumour classification, J. Cancer Res. Clin. Oncol. 116 (1990), 513-516.

[15] Y. Ichinose et al., Is T factor of the TNM staging system a predominant prognostic factor in pathologic stage I non-smallcell lung cancer?, J. Thorac. Cardiovasc. Surg. 106 (1993), 90-94.

[16] H. Isobe, H. Miyamoto, T. Shimizu, H. Haneda, M. Hashimoto, K. Inoue, S. Mizuno and Y. Kawakami, Prognostic and therapeutic significance of the flow cytometric nuclear DNA content in non-small cell lung cancer, Cancer 65 (1990), 1391-1395.

[17] K. Kayser, M. Altiner, H. Dieneman and H.J. Gabius, Changes during the last decade in clinical parameters of operated lung carcinoma patients of a Center of Thoracic Surgery and the prognostic significance of TNM, morphometric, cytometric and glycohistochemical properties, Thorac. Cardiovasc. Surg. 45 (1997), 196-199.

[18] A. Little, T. Demester and H. MacMahon, The staging of lung cancer, Sem. Oncol. 10 (1983), 56-70.

[19] C.F. Mountain, A new international staging system for lung cancer, Chest 89 (1986), 225S-233S.

[20] J.M. Oramas et al., Estudio de 244 casos de cáncer de pulmón: frecuencia, distribución y supervivencia en Santa Cruz de Tenerife, Neoplasia 6 (1989), 51-56.

[21] K.E. Ossan, H. Anton-Culver, T. Kurosaki and T. Taylor, Sex differences in lung-cancer risk associated with cigarette smoking, Int. J. Cancer 54 (1993), 44-48.

[22] G. Pearson, Current status of surgical resection for lung cancer, Chest 106 (1994), 337S-339S.

[23] T. Rice, T. Baver, G. Gephardt, S. Menendorp, D. McLain and T. Kirby, Prognostic significance of flow cytometry in non-small-cell lung cancer, J. Thorac. Cardiovasc. Surg. 106 (1993), 210-217.

[24] K. Rothman, Induction and latent periods, Am. J. Epidemiol. 114 (1981), 253-259.

[25] J. Ruckdeschel, Therapeutic options for the treatment of small cell and non-small cell lung cancer, Curr. Opin. Oncol. 5 (1993), 323-334.

[26] A.A. Sahin, J.Y. Ro, El-Naggar, J.S. Lee, A.G. Ayala, K. Feague and W.K. Hong, Flow cytometric analysis of DNA content of non-small-cell lung cancer: ploidy as a significant prognostic indicator in squamous cell carcinoma of the lung, Cancer 65 (1990), 530-537.

[27] A. Sampedro and A. Orfao, DNA Cytometric Analysis, Servicio de Publicaciones de la Universidad de Oviedo, Oviedo, Spain, 1993.

[28] H. Sather, The use of prognostic factors in clinical trial, Cancer 58 (1986), 461-467.

[29] P. Schlichting, E. Chistensen and P.K. Andersen, Prognostic factors in cirrhosis identified by Cox's regression model, Hepatology 3 (1983), 889-895.

[30] R. Severson, Cigarette smoking and leukemia, Cancer 60 (1987), 141-144.

[31] F.A. Shepherd, Screening, diagnosis and staging of the lung, Curr. Opin. Oncol. 5 (1993), 310-312.

[32] D. Tirindelli-Danessi, L. Teodori, F. Mauro, C. Modini, C. Botti and F. Cicconetti, Prognostic significance of flow cytometry in lung cancer. A 5-year study, Cancer 60 (1987), 844-851.

[33] P.C. Van Bodegom, J.P.A. Baak, C. Stroet-Van Galeen, N. Schipper, E. Wise-Brekelmans, R. Vanderschueren and S.S. Wagenaar, The percentage of aneuploid cells is significant correlated with survival in accurately staged with stage I resected squamous cell lung cancer and long-term follow-up, Cancer 63 (1989), 143-147. 
[34] L. Vindelöv and J. Christensen, A review of techniques and results obtained in one laboratory by an integrated system of methods designed for routine clinical flow cytometric DNA analysis, Cytometry 11 (1990), 753-770.

[35] M. Volm, H. Bak and E.W. Hahn, DNA and S-phase distribution and incidence of metastasis in human primary lung cancer, Cytometry 9 (1988), 183-188.

[36] M. Volm, P. Drings, J. Mattern, J. Sonka, I. Vogt-Moykoff and K. Wayss, Prognostic significance of DNA and resistancepredictive test in non-small cell lung carcinoma, Cancer 56 (1985), 1396-1403.

[37] M. Volm, E.W. Hahn, J. Matthew, I. Vogt-Moykopf and E. Weber, Five-year follow-up study of independent clinical and flow cytometric prognostic factors for survival of patients with non-small cell lung cancer, Cancer Res. 48 (1988), 2923-2928.

[38] T.H. Weissemburger, Effects of postoperative mediastinal radiation on completely resected stage II and stage III epidermoid cancer of the lung, Chest 106 (1994), 297S-301S.

[39] P. Zimmerman, M. Bint, G. Hawson and P. Pardons, Ploidy as a prognostic determinant in surgically treated lung cancer, Lancet 2 (1987), 530-533. 


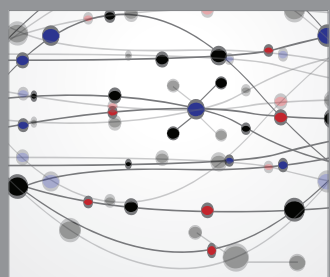

The Scientific World Journal
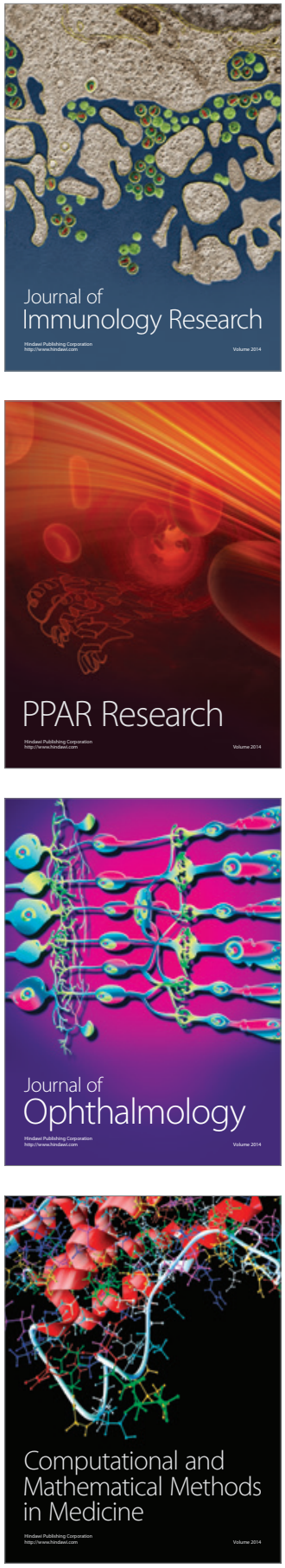

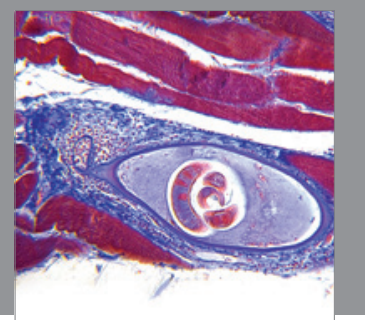

Gastroenterology

Research and Practice
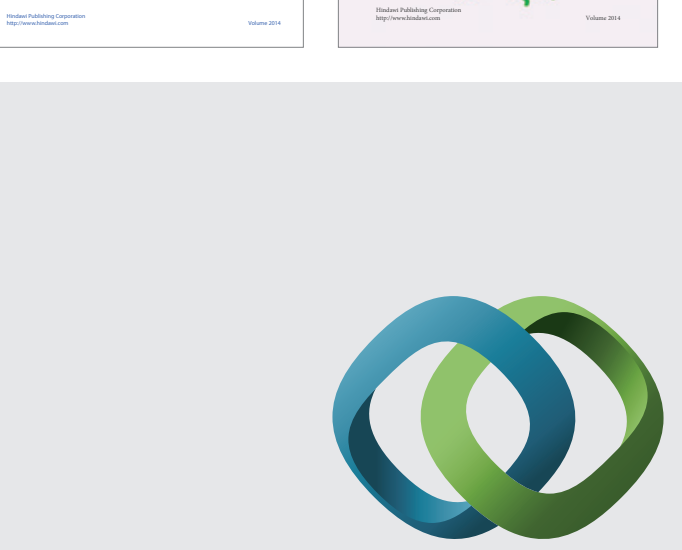

\section{Hindawi}

Submit your manuscripts at

http://www.hindawi.com
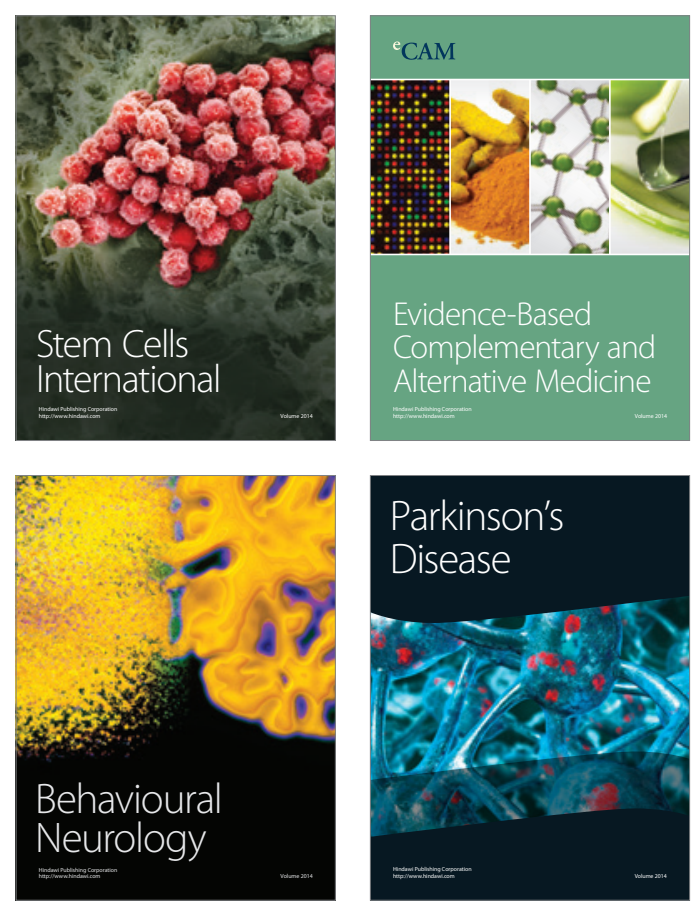

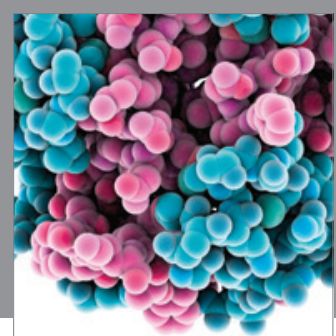

Journal of
Diabetes Research

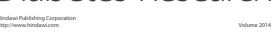

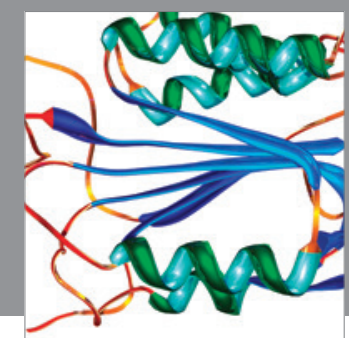

Disease Markers
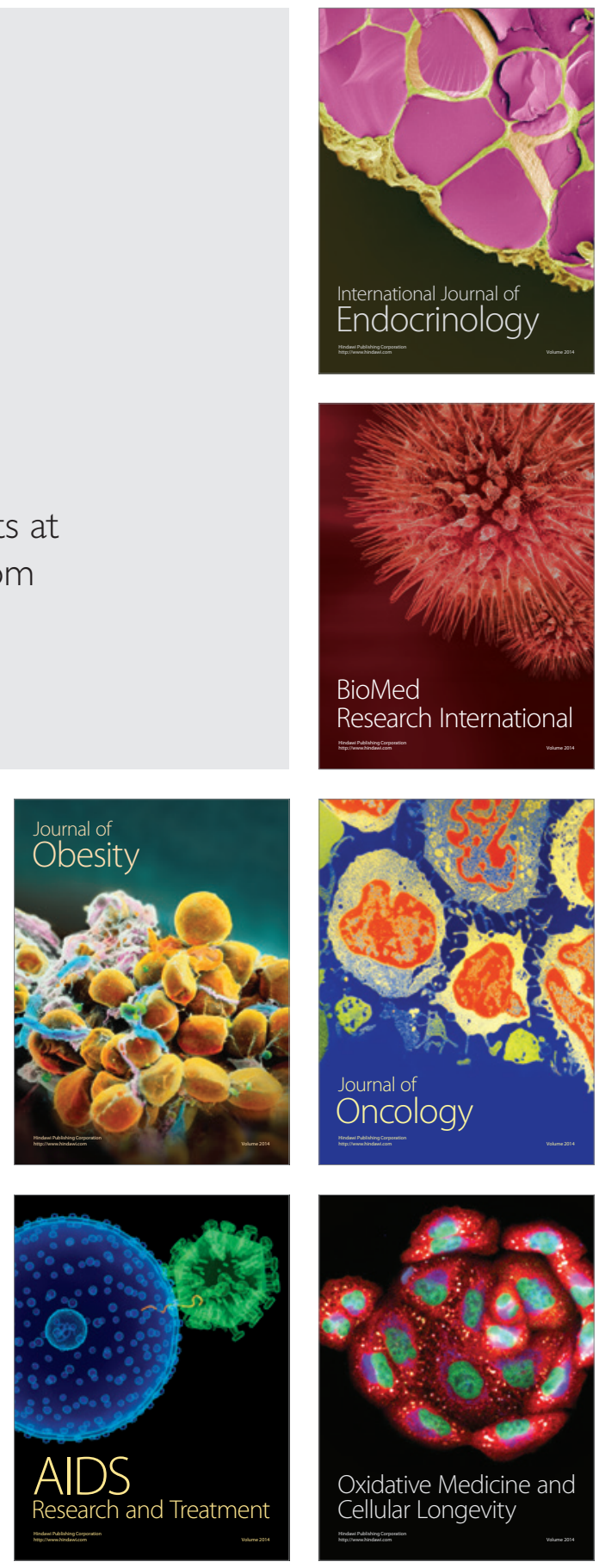